\title{
NOVAS METODOLOGIAS EM HISTÓRIA ECONÓMICA: \\ A ARQUEOLOGIA INDUSTRIAL *
}

José M. Amado Mendes

\section{Investigação histórica: inovação e factores cumulativos}

Na ciência histórica - em constante evolução, como qualquer outra ciência -, os elementos inovadores vão-se frequentemente acumulando ao legado preexistente. A propósito, escrevia, há pouco, G. Noiriel: "Diferentemente de Febvre e de Braudel, que para melhor convencer os leitores do seu génio negaram todo o valor aos trabalhos dos seus predecessores, é necessário colocar a tónica no aspecto cumulativo do trabalho dos historiadores" ('). Assim, a análise e a crítica rigorosa e cuidada das fontes, bem como a sua imprescindibilidade, a datação dos factos e a cronologia fazem parte de uma herança cujas origens remontam, pelo menos, aos

* Texto, revisto e anotado, que serviu de base à lição proferida nas Provas de Agregação, prestadas pelo autor na Universidade de Coimbra, em 15 e 16 de Julho de 1991.

(') Gérard Noiriel, "Pour une approche subjectiviste du social", Annales. E. S. C., 1989, $44 .^{\circ}$ ano,.$^{\circ}$ 6, p. 1451 (Tradução minha, como nas restantes citações efectuadas no texto, a partir de línguas estrangeiras). 
finais do século XVII. Como é sabido, foi de extraordinária importância o contributo então dado por Jean Mabillon, cuja monumental obra - De re diplomatica — veio a lume em $1681\left({ }^{2}\right)$.

Porém, desde os inícios do nosso século, aos ditos factores, até aí acumulados, outros se têm vindo a agregar. Os mais significativos distribuem-se por três níveis: fontes, temática e metodologia.

Quanto às fontes, altera-se a sua relação com o historiador, passando este a desempenhar um papel não só mais actuante como mais significativo. De acordo com a problemática, previamente detectada e definida, o investigador, através do questionário tido por mais adequado, "interroga" a fonte. Contrariamente ao lema adoptado pelos cultores da chamada "história metódica" $\left({ }^{3}\right)$ segundo o qual se devia "deixar falar a fonte" -, torna-se indispensável, por um lado, "fazê-la falar" e, por outro, saber interpretar os seus silêncios e/ou omissões. Com a adopção de novos tipos de questionários torna-se igualmente possível - e até mesmo desejável-utilizar também outros tipos de fontes, o que, efectivamente, tem vindo a suceder. Deste modo, alargou-se o próprio conceito de fonte, o que, em certa medida, induziu o historiador a aproximar-se do arqueólogo, visto aquele também ter de prestar atenção aos vestígios de diversa natureza. Como ensina Michel Foucault: "Houve um tempo em que a arqueologia, como disciplina dos monumentos mudos, dos traços inertes, dos objectos sem contexto e das coisas deixadas pelo passado, tendia para a história

(') Jean Mabillon, De re diplomatica..., reed.,Paris, Lutaciae-Parisiorum, Sumtibus Caroli Robustel, 1709; Krzysztof Pomian, "L'histoire de la science et l'histoire de l'histoire", Annales. E.S.C., $1975,30 .^{\circ}$ ano, n. ${ }^{\circ}$ 5, p. 950. Cfr. ainda G. Noiriel, op. cit., p. 1451-1452.

( ${ }^{3}$ Sobre a história ou "escola" metódica ver: Charles-Olivier Carbonell, Histoire et historiens. Une mutation idéologique des historiens français, 1865-1885, Toulouse, Privat, 1976, p. 409-451 ; Guy Bourdé e Hervé Martin, Les écoles historiques, Paris, Seuil, 1983, p. 137-170; José M. Amado Mendes, A história como ciência. Fontes, metodologia e teorização, 3." ed., Coimbra, Coimbra Editora, 1993, p. 68-73. 
e apenas visava a restituição de um discurso histórico; poder-se-ia dizer, jogando um pouco com as palavras, que a história, dos nossos dias, tende para a arqueologia - para a descrição intrínseca do monumento" $\left({ }^{4}\right)$.

Relativamente à metodologia, começa a recorrer-se, mais frequentemente, a um leque de disciplinas muito variado, ultrapassando-se largamente o quadro, demasiado restrito, das até há pouco designadas "disciplinas auxiliares" da história. O inquérito - escrito e oral —, o tratamento da informação obtido através das séries documentais, a quantificação, a interpretação do simbólico e do figurado, a cartografia e a ilustração-com o recurso a gráficos, quadros, gravuras, etc. -constituem apenas algumas das inovações introduzidas na "oficina da história" ( $\left.{ }^{5}\right)$, ao longo do nosso século.

Do ponto de vista temático, como que deixaram de existir zonas subalternas, pois, além dos eventos político-militares e diplomáticos, diversas outras facetas da realidade começaram a ser contempladas pela investigação. Entre muitos outros, têm sido e continuam a ser objecto de investigação temas como os seguintes: saúde, trabalho e lazer; costumes, mitos, ritos e atitudes perante a morte; estratificação e mobilidade social; levantamentos populares, comportamentos e acções de grupos marginais; transformações sofridas pelo meio ambiente; ciência e tecnologia. Como consequência desta nova perspectiva, não só o historiador se começou a debruçar sobre assuntos extraordinariamente variados-revelando-se a inovação, em tal domínio, como algo de muito positivo $\left({ }^{6}\right)-$, como se cons-

( ${ }^{4}$ Michel Foucault, L'archéologie du savoir, Paris, Gallimard, 1969, p. 15.

( $)$ Expressões como "oficina da história" e "oficio de historiador" têm sido muito divulgadas, especialmente pela historiografia francesa. Por exemplo, François Furet atribuiu a um dos seus livros o título de "L'Atelier de l'Histoire", do qual existe tradução portuguesa (A oficina da história, col. "Construir o passado", 8, Lisboa, Gradiva, s.d.).

$\left(^{\circ}\right)$ Cfr. Guy Thuillier e Jean Tulard, La méthode en histoire, col. "Que sais-je?", Paris, PUF, 1986, p. 28. 
tituíram novas disciplinas autónomas, entre as quais se encontra, precisamente, a história económica.

\section{História económica}

\subsection{Suas origens}

Ainda no século XVIII, alguns autores iluministas começaram a chamar a atenção para as esferas do económico e do quotidiano. A propósito, sublinhava Condorcet, numa obra publicada em 1795: "Até aqui, a história política, como a da filosofia e das ciências, não tem sido senão a história de alguns homens: o que forma verdadeiramente a espécie humana, a massa das famílias que subsiste quase inteiramente do seu trabalho tem sido esquecida" ( ${ }^{7}$ ).

Ao longo de Oitocentos, o interesse por aqueles aspectos foi-se intensificando, para o que contribuíram, entre outros factores, o materialismo histórico e o desenvolvimento industrial, técnico e científico.

Kula, por sua vez, nota que a história económica nasce juntamente com a economia política burguesa, o capitalismo e a revolução industrial $\left({ }^{8}\right)$. Começando por ser uma esfera de interesse- a partir de inícios do século XIX - , a história económica, como disciplina, só nos começos do século XX viria a alcançar a sua autono$\operatorname{mia}\left({ }^{9}\right)$.

(') A. N. de Condorcet, Esquisse d'un tableau historique des progrès de l'esprit humain, Paris, Boivin et $C^{i e}$. Editeurs, 1933, p. 200 (1. éd., póstuma, 1795).

$\left({ }^{8}\right)$ Witold Kula, Problemas y métodos de la historia económica (trad. do polaco), 3. ${ }^{\text {a }}$ ed., Barcelona, Ed. Península, 1977, p. 14.

(') W. Kula, idem, p. 14 e 25. 


\subsection{Evolução da história económica}

Paralelamente à introdução da história económica, como disciplina, no ensino superior-nos Estados Unidos da América, desde os anos 1890 e em Universidades europeias, já no nosso século $\left({ }^{10}\right)$ —, incrementa-se a respectiva investigação. Temáticas como o comércio e a revolução industrial, o movimento dos preços e dos salários e as crises económicas passaram a ser frequentemente estudadas (").

A partir do "nascimento" dos Annales (1929) $\left({ }^{12}\right)$, a história económica — frequentemente aliada à história social—passou a estar na ordem do dia. De certo modo, tratava-se de uma contrapartida à recusa (pelo menos implícita) da predominância dada, até essa altura, à história política.

Como é sabido, no âmbito da "nova história" — também, por vezes, designada "estrutural", "serial" ou "história-problema"—, o económico passou a ocupar um lugar de primeiro plano.

Posteriormente-já nos anos 1950—, com o aparecimento, nos Estados Unidos da América do Norte e na Grã-Bretanha, da "new economic history" — também chamada "cliometria" ou "história econométrica" —, novo impulso é dado à história económica, em especial através de uma nova e mais ousada metodologia. Esta caracteriza-se, essencialmente, pela explicitação das hipóteses,

$\left({ }^{10}\right)$ A primeira cadeira de história económica foi introduzida, em Harvard (Estados Unidos da América do Norte), em 1893. Na Universidade de Manchester (Grã-Bretanha) só em 1910 viria a ser criada uma cadeira de história económica (F. Mendels, "Histoire économique", André Burguière (dir. ), Dictionnaire des sciences historiques, Paris, PUF, 1986, p. 217).

(11) Sobre o assunto, ver também Vitorino Magalhães Godinho, Introdução à história económica, Lisboa, Livros Horizonte, s.d., p. 11-57 ("Da descoberta do económico até à Primeira Guerra Mundial").

${ }^{(1)}$ Ver André Burguière, "Histoire d'une histoire: la naissance des Annales", Annales. E.S.C., 1979, 34. ${ }^{\circ}$ ano, n. ${ }^{\circ}$ 6, p. 1347-1359. 
pelo uso de modelos e do contrafactual e ainda pelo recurso mais frequente à teoria política e a métodos estatísticos mais sofisticados, inclusive com apoio informático $\left({ }^{13}\right)$.

\subsection{Tendências e perspectivas em aberto}

A evolução da história económica tem-se processado, fundamentalmente, no que se reporta às fontes, aos temas de pesquisa e à metodologia.

Quanto às fontes, é de salientar a descoberta - ou mesmo a "invenção", como já foi sublinhado $\left({ }^{14}\right)$ - e a acessibilidade a novos tipos de documentos, a novas fontes primárias, até há pouco desconhecidas ou menosprezadas. Recorde-se, por exemplo, o importante papel que os arquivos das empresas e as fontes orais podem desempenhar em tal contexto $\left({ }^{15}\right)$. Por outro lado, além do acesso a novos documentos e, inclusive, do alargamento do próprio conceito de fonte - comum a outros domínios da ciência histórica —, na história económica tiveram repercussões ainda mais decisivas

$\left({ }^{13}\right)$ Ralph Andreano(dir. ),La nouvelle histoire économique. Exposés de méthodologie (trad. do inglês), Paris, Gallimard, 1977; J. Heffer, "Une histoire scientifique: La nouvelle histoire économique", Annales. E.S.C., 1977,32. ${ }^{\circ}$ ano, n. ${ }^{\circ}$ 4, p. 824-842. Como veículo importante da "new economic history", ver The Journal of Economic History, começado a publicar, em Nova Iorque, no ano de 1941 e do qual saiu, em Junho de 1990, o vol. L, $\mathbf{n}^{\circ} \mathbf{2}$.

${ }^{\left({ }^{4}\right)}$ René Girault et al., La recherche historique en France depuis 1965, Paris, C.N.R.S., 1980, p. 47.

(15) Cfr. R. Girault et al., ibidem. Sobre os arquivos de empresa e o papel da história "na" empresa, ver Maurice Hamon e Félix Torres (dir.), Mémoire d'avenir. L'histoire dans l'entreprise. Actes du 1" Colloque d'Histoire appliquée aux entreprises organisé par Saint-Gobain et Public Histoire. Blois 21 -22 mai 1985, Paris, Ed. Economica, 1987. Para se obter uma visão actualizada acerca do aproveitamento das fontes orais pelo historiador, ver Dominique Aron-Schnapper e Danièle Hanet, "D'Hérodote au magnétophone: sources orales et archives orales", Annales. E.S.C., 1980, 35..$^{\circ}$ ano, n. ${ }^{\circ} 1$, p. 183-199. 
a integração da fonte na respectiva série e a valorização metodológica desta. Essa mudança de perspectiva tornava-se, aliás, condição "sine qua non" para se poder efectuar a transição da história factual para a história estrutural que, pela sua própria natureza, é também "história serial", como lhe chamou Pierre Chaunu $\left({ }^{16}\right)$.

Em relação aos temas de pesquisa, generalizou-se uma certa perspectiva "democratizante". Os "projectores" do historiador começaram, finalmente, a orientar-se para esse vasto sector da "história anónima", para utilizar a expressão de S. Giedion $\left({ }^{17}\right)$. O quotidiano, o comum, os objectos e artigos de uso vulgar, as estruturas, os utensílios e mecanismos utilizados na produção e/ou nos transportes e comunicações, bem como certos grupos sociais entram assim, justamente, no âmbito da investigação histórica $\left({ }^{18}\right)$. Em consequência disso, o papel do historiador alarga-se e revaloriza-se. Ao referir-se a esse facto, Marcel Gillet sublinha "quanto os historiadores do século XX vêem a sua função alargar-se: eles não somente acumulam, graças aos arquivos orais que organizam, testemunhos sobre o vivido de mutações decisivas, como ao participarem nos esforços de comunidades cuja identidade se encontra ameaçada, contribuem para preservar, quer o património industrial, quer o património etnológico" $\left({ }^{19}\right)$. Trata-se, afinal, de uma inter-

$\left({ }^{16}\right)$ Pierre Chaunu, Histoire quantitative, histoire sérielle, "Cahiers des Annales", 37, Paris, A. Colin, 1978.

(') S. Giedion, La mécanisation au pouvoir. Contribution à l'histoire anonyme, t.I: Les origines (trad. do inglês), Paris, Centre Georges Pompidou/CCI, 1980, p. 15-19. Sobre o conteúdo da expressão "história anónima", ver p. 16 da obra citada.

${ }^{(18)}$ Cfr. Paul Bairoch e Bouva Etemad, "La littérature périodique d'histoire économique contemporaine", Annales. E.S.C., 1987, 42. ${ }^{\circ}$ ano,n. ${ }^{\circ}$, em especial p. 376-380; Dominique Aron-Schnapper e Danièle Hanet, "D'Hérodote au magnétophone: sources orales et archives orales", Annales. E.S.C., 1980, 35..$^{\circ}$ ano, n. ${ }^{\circ}$ 1, p. 185.

(') Marcel Gillet, "Patrimoine industriel et patrimoine ethnologique: l'aire culturelle septentrionale (nord de la France - Belgique)", Annales. E.S.C., 1980, 35..$^{\circ}$ ano, n. ${ }^{\circ}$, p. 167-175. 
-relação. Por um lado, o aproveitamento de novas fontes e/ou respectivas séries possibilita o estudo de novas temáticas. Por outro, a investigação de novos temas induz o historiador a recorrer a novos tipos de fontes.

Sob o ponto de vista da metodologia, a história económica começou a recorrer, já não apenas às tradicionais ciências "auxiliares" - paleografia e diplomática, numismática, arqueologia, heráldica, sigilografía, etc.-, mas também a diversas outras disciplinas, dotadas da mesma dignidade científica e, por isso mesmo, hoje consideradas ciências "complementares" ou "colaboradoras", usando a terminologia de Robert Delort $\left({ }^{20}\right)$.

Entre as ciências a que a história económica tem vindo a recorrer - segundo uma perspectiva interdisciplinar, cada vez mais necessária-, contam-se as seguintes: demografia, geografia $\left({ }^{21}\right)$, economia $\left({ }^{22}\right)$, sociologia, antropologia e estatística. Como é do conhecimento geral, o papel da estatística tem sido extraordinariamente relevante, dada a importância do quantitativo em história económica. Recorda-se, inclusive, que a história, recentemente adjectivada de "experimental" por Daniel S. Milo, tem no quantitativo um dos mais sólidos alicerces $\left({ }^{23}\right)$. Porém, dadas algumas limitações do próprio método quantitativo, a sociologia poderá desempenhar uma função complementar bastante significativa, desde que entre ela e a história se inventem novas formas de diálogo $\left({ }^{24}\right)$.

$\left({ }^{20}\right)$ Robert Delort, Introduction aux sciences auxiliaires de l'histoire, col. "U", Paris, A. Colin, 1969, p. 9-10.

${ }^{(1)}$ Marcel Roncayolo, "Histoire et géographie: les fondements d'une complémentarité", Annales. E.S.C., 1989, 44. ${ }^{\circ}$ ano, p. 1427-1434.

${ }^{(2)}$ Robert Boyer, "Économie et histoire: vers de nouvelles alliances?", Annales. E.S.C., $1989, \mathrm{n} .^{\circ}$ 6,p. 1397-1426.

$\left({ }^{23}\right)$ Daniel S. Milo, "Pour une histoire expérimentale, ou la gaie histoire", Annales. E.S.C., 1990,45. ${ }^{\circ}$ ano, n. ${ }^{\circ}$ 3, p. 717-734.

$\left.{ }^{(24}\right)$ Cfr. Gérard Noiriel, "Pour une approche subjectiviste du social", Annales. E.S.C., $1989,44 .^{\circ}$ ano, n. ${ }^{\circ}$, p. 1449. 
Estamos ante um processo que continua em aberto. Aliás, a receptividade à inovação, do ponto de vista historiográfico, não é um dos contributos menores legados pela nova história. No que à história económica diz respeito, há que salientar, segundo uma perspectiva pluridisciplinar, as seguintes vertentes: a) por um lado, os relevantes "serviços" prestados por aquela a outras disciplinas, entre as quais se podem mencionar a história da arte, a história da literatura, a história da ciência e das técnicas, os estudos sobre o desenvolvimento, etc. Assim, a história económica, além de constituir "lugar de uma alternativa aberta no âmbito das ciências sociais" - c o mo ensina Robert Boyer $\left({ }^{25}\right)$-, poderá dar um contributo significativo mesmo a outros domínios do saber; b) por outro lado, a própria história económica só beneficiará se continuar a trilhar novos caminhos, para o que as metodologias e experiências de outras disciplinas muito poderão contribuir.

Há, pois, que "interrogar" novas fontes — não só escritas como materiais, orais, figuradas e registadas —, focar novas temáticas, aproveitando as achegas trazidas por outras ciências, cuja complementaridade se torna cada vez mais evidente. É que, como já foi sublinhado por Witold Kula, "não existe nenhuma disciplina histórica capaz de resolver os seus próprios problemas, utilizando somente os respectivos materiais e métodos" $\left({ }^{26}\right)$.

Vejamos, seguidamente, o contributo que poderá ser dado pela arqueologia industrial, com vista a aperfeiçoar a metodologia da história económica.

${ }^{(25)}$ Ver R. Boyer, op. cit., p. 1416-1420.

${ }^{(26)}$ Witold Kula, Problemas y métodos de la historia económica (trad. do polaco), 3. ${ }^{\text {a }}$ ed., Barcelona, Ed. Península, 1977, p. 68. 


\section{Arqueologia industrial}

\subsection{Origens e objecto}

Como disciplina autónoma e devidamente estruturada, a arqueologia industrial está ainda na infância, já que apenas remonta aos anos 50 e 60 da nossa centúria. Surgiu num contexto caracterizado, essencialmente, pelos seguintes factores: a) reconstrução, acelerada e profunda, que se verificou no pós-guerra e em consequência do próprio conflito de 1939-45; b) rápido crescimento urbano, onde o antigo ou mesmo o apenas obsoleto passaram a ser encarados sobretudo como bloqueios a carecer de imediata eliminação; c) a consequente destruição de alguns monumentos industriais bastante significativos, não obstante os protestos em sentido contrário. Ficou célebre, sob este ponto de vista, a demolição da "Euston Station" - construída, em Londres, entre 1835 e 1839-, cujo vestíbulo, dórico, assinalava triunfalmente o "terminus" da via férrea da capital britânica a Birmingham $\left({ }^{27}\right)$. Ao facto se refere Maurice Doumas, nos seguintes termos: "Numerosas sociedades e organizações intervieram com vivacidade para que este testemunho histórico do triunfo da sociedade industrial inglesa fosse poupado. Mas elas não foram ouvidas e a destruição teve lugar em 1962" $\left({ }^{28}\right)$. Após um primeiro "alerta" lançado pela Bélgica $\left({ }^{29}\right)$ e pela Grã-Bretanha $\left({ }^{30}\right)$, outros países - entre os quais,

$\left.{ }^{27}\right)$ R. A. Buchanan, "Industrial archaeology: Retrospect and prospect", Antiquity, 1970, vol. XLIV, n. ${ }^{\circ}$ 176, p. 281 ; Maurice Daumas, L'archéologie industrielle en France, Paris, Robert Laffont, 1980, p. 429.

${ }^{(28)}$ M. Daumas, ibidem.

$\left.{ }^{(29}\right)$ R. Évrard, "Une belle découverte d'archéologie industrielle: le fourneau Saint-Michel", Les Vennes, octobre 1950, n. ${ }^{\circ}$ 10, p. 4-6.

$\left.{ }^{(30}\right)$ Michael Rix, "Industrial archaeology", The amateur Historian, 1955, vol. 2, n. ${ }^{\circ}$ 8, p. 225-229. 
Itália, Suíça, França, Espanha, Portugal, Estados Unidos da América do Norte e Canadá - desenvolveram certas actividades no âmbito da arqueologia industrial. Naturalmente que, de forma difusa e embrionária, já anteriormente se manifestavam algumas das preocupações que, mais tarde, viriam a caracterizar, como disciplina, o exercício da arqueologia industrial. Com efeito-mesmo circunscrevendo-me só a Portugal —, que faziam um Oliveira Martins (ao empenhar-se na obtenção de objectos, para expor no Museu Industrial e Comercial do Porto $\left({ }^{31}\right)$ ), um Charles Lepierre (ao analisar grande número de amostras de argila $\left({ }^{32}\right)$ ) ou um José Queirós (ao estudar, através da observação directa, artigos de cerâmica $\left.\left({ }^{33}\right)\right)$, senão arqueologia industrial "avant la lettre"? Isto para já não aludir a Sousa Viterbo, a cuja competência, lucidez e intuição se ficou a dever, com uma antecipação de mais de meio século, a paternidade da expressão "arqueologia industrial". De facto, contrariamente ao que tem sido inúmeras vezes afirmado em trabalhos da especialidade - embora, por vezes, já se comece a repor a verdade, quanto ao contributo português —, muito antes do inglês Michael Rix ter utilizado a dita expressão, em $1955\left({ }^{34}\right)$, já Sousa Viterbo tinha proposto o seu uso, em artigo dado à estampa em 1896, intitulado precisamente "Archeologia industrial portuguesa" $\left({ }^{35}\right)$. De forma

$\left({ }^{31}\right)$ Além de outras diligências, Oliveira Martins solicitou a Jaime Batalha Reis que lhe remetesse, dos Estados Unidos da América do Norte e da Grã-Bretanha, objectos que pudesse expor no referido museu (Biblioteca Nacional de Lisboa, Esp. E 20 [Oliveira Martins]).

$\left.{ }^{32}\right)$ Charles Lepierre, "Estudo chimico e technologico sobre a ceramica portugueza moderna", 2. ${ }^{a}$ ed. (anotada), Boletim do Trabalho Industrial, 1912, n. 78 (1. ${ }^{a}$ ed., em livro, Lisboa, Imprensa Nacional, 1899).

$\left({ }^{33}\right)$ José Queirós, Cerâmica portuguesa e outros estudos. Organização, apresentação, notas e adenda iconográfica à edição de 1907 por José Manuel Garcia e Orlando da Rocha Pinto, Lisboa, Presença, 1987.

$\left.{ }^{(34}\right)$ Cfr. supra, nota 30.

$\left.{ }^{(35}\right)$ Sousa Viterbo, "Archeologia industrial portuguesa-Os moinhos", O Archeologo Português, 1896, vol. II, n. ${ }^{\circ} \mathrm{s} 8$ e 9 (Reeditado, com uma introdução de José Lopes 
pertinente e ainda actualizada, interrogava Sousa Viterbo: "Existe a archeologia da arte, porque não háde existir a archeologia da industria?". Prosseguindo, um pouco adiante, afirmava o autor: "Nas grandes exposições modernas é costume apresentar aos olhos do visitante o desenvolvimento completo por que passa qualquer matéria-prima em todas as sucessivas e complicadas metamorphoses, até se converter no mais surprehendente artefacto. Maravilha tanta força de engenho dispendida nos mais aperfeiçoados machinismos, mas mais maravilhado ficaria o espectador se presenceasse todos os processos e todos os instrumentos e apparelhos seguidos e adoptados desde os tempos mais remotos até aos nossos dias. O Museu que realizasse semelhante ideia seria a escola mais instructiva do mundo". E, para que não ficassem dúvidas sobre a sua perspectiva de enquadramento da evolução tecnológica no longo prazo-o que continua a ser metodologicamente correcto $\left({ }^{36}\right)-$, acrescenta: "Uma pagina do Apocalypse de Lorvão do seculo XII é a história animada da vindima: o lagar que lá vemos desenhado parece não ter soffrido aperfeiçoamento no decorrer de tantas centenas de annos. Em muitas casas de lavoura ainda vereis o mesmo typo, estacionario, de uma longevidade millenaria" $\left({ }^{37}\right)$.

Entretanto, poder-se-ia perguntar: actualmente, qual o significado de arqueologia industrial? Segundo uma definição já clássica, a arqueologia industrial é descrita como "um campo de estudo relacionado com a investigação, levantamento, registo e por vezes salvaguarda de monumentos industriais. Ela tem por objecto, sobretudo, apreender o significado de tais monumentos no contexto

Cordeiro, pela "MURALHA — Associação de Guimarães para a Defesa do Património", Guimarães, 1896).

$\left({ }^{36}\right)$ Ver, a propósito, Jorge Borges de Macedo, A problemática tecnológica no processo de continuidade República - Ditadura Militar - Estado Novo, Lisboa, 1979. Sep. de Economia, vol. III, n. ${ }^{\circ}$.

$\left.{ }^{(37}\right)$ Sousa Viterbo, op. cit., reed., p. 5-6. 
da história social e tecnológica" $\left({ }^{38}\right)$. O património industrial objecto da arqueologia industrial - é constituído por monumentos industriais e sítios de natureza diversa, abrangendo uma grande variedade de componentes, dos seguintes domínios: estruturas, utensílios e tecnologias artesanais e industriais; sistemas (ou seus vestígios) de transporte e comunicações; e equipamentos colectivos, referentes ao abastecimento - energétigo, de água ou alimentar-, à saúde, ao ensino e ao aproveitamento dos tempos livres. Trata-se de uma área muito vasta e multifacetada, em relação à qual se tem vindo a notar ultimamente uma maior receptividade. Sobre o assunto, destaca Neil Cossons: "Para um número de pessoas cada vez maior, os motores e máquinas, fábricas, manufacturas e armazéns, canais e vias férreas que acabaram por dominar a paisagem nos últimos dois séculos têm-se tornado profundamente significativos, como parte do nosso património cultural" $\left({ }^{39}\right)$.

\subsection{Enquadramento teórico-metodológico da arqueologia industrial}

Como se acaba de expor, o objecto da arqueologia industrial é muito amplo. Uma vez que aquela engloba, praticamente, todos os vestígios materiais do processo de desenvolvimento socioeconómico, já se identificou a arqueologia industrial com a "arqueologia do mundo moderno e contemporâneo" $\left({ }^{40}\right)$.

$\left({ }^{38}\right)$ R. A. Buchanan, The theory and practice of industrial archaeology, Bath, 1968, p. I, apud M. J. T. Lewis, "Industrial archaeology", Carlo M. Cipolla (ed.), The Fontana Economic History of Europe, vol. 3: The Industrial Revolution, 1700-1914, Londres Harvester Press/Barnes \& Noble/Fontana Books, 1976, p. 575.

${ }^{39}$ ) Neil Cossons, The BP book of industrial archaeology, 2." ed., Londres, David \& Charles, 1987, p. 13.

$\left({ }^{40}\right)$ Xavier Barral i Altet, "Arqueología industrial o arqueologia del mundo moderno y contemporáneo", A Distancia [Madrid, Universidad Nacional de Educacion a Distancia], Junho/89, p. 36-42. 
Mas tratar-se-á, efectivamente, de "arqueologia"? A despeito de uma ou outra voz discordante $\left.{ }^{41}\right)$, a expressão "arqueologia industrial" está já consagrada e é geralmente aceite. Com efeito, além de se lhe poder aplicar uma das definições clássicas de arqueologia-isto é, "a recuperação, descrição e estudo sistemáticos da cultura material do passado" $\left({ }^{42}\right)$ —, também a arqueologia industrial privilegia, como fontes, os testemunhos materiais.

Ainda que só ocasionalmente tenha necessidade de recorrer às escavações $\left({ }^{43}\right)$ - trata-se, por isso, de uma "arqueologia de cota positiva" - a arqueologia industrial tem o seu lugar entre os outros ramos da arqueologia histórica, dos quais fazem parte, nomeadamente, a arqueologia das primeiras civilizações (pré-clássicas e clássicas), a arqueologia medieval e a arqueologia pós-medieval ou moderna $\left({ }^{44}\right)$. A arqueologia industrial fica assim reservado, essencialmente, o período cronológico da chamada "civilização industrial", embora com possibilidade de, sempre que necessário, remontar a períodos anteriores. Poderia ainda acrescentar-se que, embora de modo indirecto, as novas concepções de "arqueologia" e de

( ${ }^{(1)}$ Cfr. entre outros trabalhos, "Entrevista com Jorge Alarcão", Vértice, 1989,18, p. 83-84. Todavia, mais do que discordar do uso da expressão "arqueologia industrial" desde que, obviamente, se use metodologia adequada-, o que Jorge de Alarcão contesta é a sua aplicação ao estudo de certas temáticas—como, por exemplo, "estudo da produção de vidros de uma determinada fábrica, estudada através de catálogos" —, sem o recurso às fontes materiais.

${ }^{\left({ }^{4}\right)}$ Victor M. Fernandez Martínez, Teoria y método de la arqueologia, Madrid, Ed. Síntesis, 1989, p. 10.

$\left({ }^{43}\right)$ Algumas experiências já efectuadas, por exemplo, em Pedreanes, Marinha Grande - alto-forno -, Coina, concelho do Barreiro - fábrica de vidros, do reinado de $D$. João V - e Motril, Granada (Espanha) - indústria açucareira - revelam o importante contributo que, em certas circunstâncias, pode ser dado pelo método das escavações.

(") Além dos referidos ramos da arqueologia - a que poderíamos chamar geral - já se começam a individualizar domínios mais específicos, baseados em certas temáticas e especializações. Entre outros, podem indicar-se os seguintes exemplos: arqueologia funerária, arqueologia mineira, arqueologia subaquática e arqueometalurgia. Sobra as duas últimas ver alguns elementos em A Distancia (cit. supra, nota 40), p. 43-53. 
"arquivo", propostas, respectivamente, por Michel Foucault e por Adi Ophir, reforçam o fundamento teórico do uso da expressão "arqueologia industrial". No primeiro caso, ao libertar o conceito de "arqueologia" da escravização ao método (centrado nas escavações) com que geralmente se identificava, Foucault ajudou a dilatar o seu âmbito a novos domínios, por analogia com a "arqueologia do saber". No segundo, Ophir, ao abranger pelo conceito de "arquivo" novas realidades, contribuiu para dignificar o trabalho de campo e as próprias fontes materiais, colocando estas em pé de igualdade com as fontes arquivísticas tradicionais, em geral reduzidas à documentação escrita. Comprovam o que se acaba de indicar as seguintes afirmações do autor: "O elemento físico, ou figurativo - um osso, uma pedra, um tipo de escrita-, ficou dotado da sua capacidade significante quando foi arrancado ao seu contexto original de existência, quando se introduziu um intervalo entre este contexto e o discurso histórico que o percebe como um sinal" $\left({ }^{45}\right)$. "Como a própria realidade histórica — sublinha ainda Ophir — o arquivo não é fechado; é uma totalidade destotalizada através da qual o passado fala ao presente" $\left({ }^{46}\right)$.

\subsection{Evolução e novas perspectivas da arqueologia industrial}

Do vasto campo oferecido pela arqueologia industrial, só uma parte muito reduzida tem sido explorada. Porém, já é possível vislumbrarem-se algumas tendências e perspectivarem-se novas hipóteses de abordagem. Após uma primeira fase em que - por exemplo, na Grã-Bretanha - se deu especial atenção aos factores tecnológicos, outros começaram a ser também contemplados. p. 737.

$\left(^{45}\right)$ Adi Ophir, "Des ordres dans l'archive", Annales. E.S.C., 1990, $45 .^{\circ}$ ano, n. ${ }^{\circ}$ 3,

(') A Ophir, idem, p. 739. 
Assim, a arquitectura industrial tem sido, desde há algum tempo, muito estudada, não só devido à sua importância— histórico-cultural e até económica, do ponto de vista da reutilização dos respectivos edifícios $\left({ }^{47}\right)$ - como em virtude do papel que desempenha no processo de inventariação. Com efeito, em países como a Áustria, Grã-Bretanha, França e Espanha, numerosos monumentos industriais-antigas instalações fabris ou de actividades ligadas ao abastecimento-têm sido referenciados e estudados, passando a integrar, de pleno direito, os respectivos inventários, elaborados na área do património cultural e/ou do património industrial $\left({ }^{48}\right)$.

Por sua vez, em Itália têm sido realizados estudos muito interessantes e promissores, adoptando-se as seguintes perspectivas: análise conjugada da inovação com a tradição $\left({ }^{49}\right)$; o factor estético no património industrial; as componentes sociais e ideológicas, perspectivadas através dos monumentos e sítios industriais $\left({ }^{50}\right)$.

Igualmente os transportes e comunicações têm sido objecto de investigação, ainda que, por vezes, esta apareça influenciada por uma certa tradição — na linha dos coleccionadores de raridades ficando de parte largos segmentos das respectivas actividades.

Como se poderá deduzir do balanço sumário efectuado, afigura-se conveniente explorar algumas vias já ensaiadas e/ou enveredar

$\left(^{(77}\right)$ Ver, sobre o assunto, "Adaptive reuse of industrial monuments", TICCIH. Industrial Heritage-Austria 1987, Transactions 2: Conference Papers and results, Ute Georgeacopol - Winischhofert. Peter Swittalek. Manfred Wehdorn, 1990, p. 83-201.

$\left({ }^{48}\right)$ Ver alguns exemplos em Les inventaires du patrimoine industriel. Objectifs et méthodes. Hôtel de Vigny, Paris. Mars. 1986, Paris, Ministère de la Culture et Communication, 1987.

$\left({ }^{49}\right)$ Sobre as estreitas relações entre a inovação e a tradição, é de elementar justiça recordar a excelente actividade que está a ser desenvolvida pela "Casa dell' Innovazione e Patrimonio Industriale - Instituzione Aldini-Valeriani", quer do ponto de vista museológico, quer através da publicação Scuolaofficina - Periodico di Cultura Tecnica (da qual saiu em Dezembro de 1990 o n. $^{\circ}$ 2, correspondente ao 9. ${ }^{\circ}$ ano).

$\left({ }^{50}\right)$ Cfr. Al do Castellano (dir. ), La macchina arrugginita. Materiali per un 'archeologia dell'industria, Milão, Feltrinelli, 1982, passim. 
por novos caminhos, aproveitanto as enormes potencialidades do património industrial. Entre outras, parecem-me dignas de ser postas em prática acções do seguinte tipo: o estudo da tecnologia no longo prazo, desde finais da Idade Média até à actualidade; a análise das formas e modelos dos produtos, sob a perspectiva do "design"; a inventariação do património industrial, integrada nas ópticas da "história anónima" $\left(^{51}\right)$ e da história local; o recurso ao património industrial, na investigação concernente à história das empresas. Escusado será recordar que, com o desenvolvimento da arqueologia industrial, virão a beneficiar diversas outras disciplinas, dado tratar-se de um domínio ao qual também se aplica, pelo menos em parte, aquilo que tem sido salientado sobre a "história não escrita" ou a "história sem textos" $\left({ }^{52}\right)$.

\section{A arqueologia industrial como ciência colaboradora e complementar da história económica}

\subsection{Fontes}

Uma das diferenças fundamentais entre a história económica e a arqueologia industrial é a seguinte: enquanto aquela privilegia por vezes de forma exclusiva — as fontes escritas — , esta baseia-se essencialmente nas fontes materiais, sem deixar de poder recorrer, de modo complementar, a outros tipos de fontes. Assim, através do recurso às referidas fontes materiais - , pela via metodológica da arqueologia industrial —, é possível superar, pelo menos em parte,

( $\left.{ }^{51}\right)$ S. Giedion, op. e loc. cits.

${ }^{(2)}$ Ver "Histoire non écrite", Annales. E.S.C., 1973,28. ${ }^{\circ}$ ano, n. ${ }^{\circ} 1$, p. 5 e 88.; André Leroi-Gourhan, "L'histoire sans textes", Charles Samaran (dir.), L Histoire et ses méthodes, Bruges, Gallimard, 1961, p. 217-249. 
a ausência, a omissão e os próprios erros - conscientes ou inconscientes - dos testemunhos escritos. Em muitos casos - empresas e outros géneros de organizações - , a documentação escrita tem vindo a desaparecer a um ritmo acelerado, por falta de espaço, recursos e/ou sensibilização ou ainda devido à "destruição criadora" — inerente à inovação —, de que fala Schumpeter. A propósito sublinha este autor: "A abertura de novos mercados, estrangeiros ou nacionais, e o desenvolvimento da organização da produção, desde a oficina artesanal e a manufactura até às grandes firmas [...], ilustram o mesmo processo de mutação industrial - se me é permitido usar esta expressão biológica—que revoluciona incessantemente a estrutura económica a partir de dentro, destruindo o antigo e criando continuamente elementos novos" $\left({ }^{53}\right)$. Todavia, noutros casos-actividades artesanais ou industriais de reduzida dimensão, certas invenções e inovações-, essa documentação (quase) nunca existiu, pelo que as fontes materiais constituem praticamente as únicas disponíveis $\left({ }^{54}\right)$.

\subsection{Temáticas}

São diversas as áreas ou subáreas da história económica que a arqueologia industrial pode ajudar a esclarecer. A tecnologia, cuja continuidade, desde os tempos pré-históricos até à actualidade, já foi realçada por A. Leroi-Gourhan, só através dos testemunhos materiais pode ser compreendida. O referido autor fundamenta assim a sua posição: "A tecnologia constitui um ramo particular-

${ }^{\left({ }^{3}\right)}$ Joseph A. Schumpeter, Capitalismo, socialismo y democracia (trad. do inglês), Madrid, Aguilar, 1961, p. 120-121.

$\left.{ }^{\left({ }^{4}\right.}\right)$ Sobre o importante papel das fontes materiais, para a história económica, ver ainda Jorge Borges de Macedo, "Arqueologia industrial", Enciclopédia Luso-Brasileira de Cultura, 21." vol. (2. ${ }^{\circ}$ suplemento), Lisboa-São Paulo, 1986, cols. 115-118. 
mente importante entre as disciplinas etnológicas, pois é a única que evidencia uma continuidade total no tempo, é a única que permite apreender os primeiros actos propriamente humanos e acompanhá-los de milénio em milénio até ao limiar dos tempos actuais. Quando se recua no passado — prossegue o autor —, os diferentes ramos da informação etnológica morrem mais ou menos rapidamente: as tradições orais desaparecem com a última geração que as transmitiu, as tradições escritas depressa escasseiam e o século XVI é já mudo para a grande maioria dos povos e são apenas os produtos das técnicas e da arte que permitem recuar mais no tempo, sempre que as circunstâncias permitiram a sua sobrevivência" $\left({ }^{55}\right)$. Porém, a referida evolução da tecnologia, em cadeia, longe de se verificar só em épocas recuadas, tem-se processado igualmente em períodos mais recentes, os quais constituem o quadro cronológico "preferido" pela arqueologia industrial. Também neste caso se tornaram pertinentes os ensinamentos de Leroi-Gourhan, ao sublinhar: "Quando tivermos de procurar saber o que é a invenção ser-nos-á necessário afirmar que a invenção pura, ex nihilo, é de apreensão impossível.

Para que as técnicas evoluam, é preciso que a aquisição se agarre a qualquer coisa preexistente, mesmo longínqua ou inverosímil. $\mathrm{O}$ motor de explosão teve origem nas máquinas hidráulicas do século XVII, na roda de fiar, na marmita de Papin (uma vez mais se pode levar a análise ao infinito: é uma demonstração suplementar da continuidade do meio técnico)" $\left({ }^{56}\right)$.

O que fica exposto é facilmente verificável, através da observação directa de tecnologias e processos de trabalho, relativos a diferentes

$\left({ }^{55}\right)$ André Leroi-Gourhan, Evolução e técnicas, I: O homem e a matéria (trad. do francês), Lisboa, Ed. 70, 1984, p. 11.

${ }^{\left({ }^{56}\right)}$ André Leroi-Gourhan, Evolução e técnicas, II: O meio e as técnicas (trad. do francês), Lisboa, Ed. 70, 1984, p. 261. 
estádios de evolução. Entre outros, constituem exemplos bastante elucidativos o descasque de arroz, no Baixo Mondego, ou a produção vidreira, em Oliveira de Azeméis e na Marinha Grande. Também as transformações, verificadas no que respeita ao aproveitamento das fontes energéticas - tema nuclear da própria industrialização-, muito beneficiarão se forem investigadas com o apoio da arqueologia industrial. Como já foi notado, "em muitos campos o progresso tecnológico implicou a substituição de matérias-primas e combustíveis vegetais por matérias e combustíveis de origem mineral e fóssil. A história da tecnologia é, em boa parte, uma história desta substituição" $\left({ }^{57}\right)$.

Além do que já se conhece, sobre os efeitos do aproveitamento do carvão-nomeadamente graças à máquina a vapor, factor essencial da primeira fase da industrialização - , há que aprofundar as modalidades e consequências da utilização de outros tipos de energia. Por exemplo, a energia eólica, geralmente associada apenas à moagem, foi também utilizada na Flandres Ocidental (Bélgica), na preparação do linho, devido à invenção, cerca de 1860 , do famoso espadelador flamengo $\left({ }^{58}\right)$. Por sua vez, quanto à energia hidráulica, muito há igualmente a esclarecer, na já longa cadeia da evolução tecnológica, desde a nora e o rodízio até às gigantescas rodas e turbinas hidráulicas, às quais se tem ficado a dever a possibilidade do aproveitamento da "hulha branca".

${ }^{\left({ }^{57}\right)}$ Antoni Maczak e William N. Parker, "Recursos naturales y desarollo económico", Jerzy Topolski et al. Historia económica: nuevos enfoques y nuevos problemas. Comunicaciones al Séptimo Congreso Internacional de Historia Económica, Barcelona, Ed. Crítica, 1981, p. 84.

$\left.{ }^{(58}\right)$ A. Linters, Archéologie et tourisme industrielles en Flandre (Belgique). Les expériences de la 'Vlaamse Vereniging voor Industriele Archeologie' (Association Flamande d'Archéologie Industrielle). Texte de la communication faite lors des I Jomadas Ibericas del Patrimonio Industrial y de la Obra Publica. Sevilla, le 3 Octobre 1990, p. 10. 
Não obstante tratar-se de um processo ainda em curso, a mecanização do lar - para me servir de uma expressão de S. Giedion-ainda não se encontra suficientemente estudada. Sucede até, em muitos casos, que "quanto mais nos aproximamos da nossa época, menos precisos são os dados históricos" $\left({ }^{59}\right)$. Como recorda, a título de exemplo, Giedion, "no estado actual das pesquisas, ainda não se consegue determinar o local de origem do aspirador moderno" $\left({ }^{60}\right)$. Por vezes, conhece-se o ano em que determinado electrodoméstico se tornou de uso corrente. Assim, "parece que os pequenos aparelhos como as ventoinhas, os ferros de engomar, as torradeiras e os secadores, figuram pela primeira vez nos catálogos em 1912; o aspirador em 1917; a panela eléctrica em 1930 e o frigorífico eléctrico em 1932". "A mecanização da cozinha- nota Giedioncoincide com a mecanização da alimentação" $\left.{ }^{61}\right)$.

Contudo, sobre outras questões, relacionadas com o dito equipamento doméstico, já pouco se sabe. Com efeito, são escassos os estudos sobre assuntos do seguinte teor: evolução dos electrodomésticos, para o que se torna necessário organizar colecções completas, recorrendo, para o efeito, à metodologia da arqueologia industrial; economia de mão-de-obra, a médio e longo prazo; a redução da oferta de trabalho doméstico; a libertação da mulher para exercer a sua actividade profissional fora do domicílio.

Em suma: a arqueologia industrial, analisando evolutivamente os aparelhos de que nos temos servido, poderá dar um valioso contributo para o esclarecimento dos assuntos enunciados, no âmbito da "história anónima". Acrescente-se, aliás, que o papel da

$\left.{ }^{(59}\right)$ Siegfried Giedion, La mécanisation au pouvoir. Contribution à l'histoire anonyme, t. III: La mécanisation à la maison, Paris, Centre Georges Pompidou/CCI, 1980, p. 63.

(") S. Giedion, idem, t. III, p. 63-64.

${ }^{\left({ }^{11}\right)}$ S. Giedion, La mécanisation au pouvoir, t.I: Les origines, Paris, Centre Georges Pompidou/CCI, 1980, p. 15-19. 
arqueologia industrial, sob a perspectiva que se acaba de focar, não se restringe à história económica, já que se integra perfeitamente numa das novas tendências da historiografia. A propósito, já foi salientado: "o alargamento da nossa imagem do passado: um novo interesse pelas classes sociais, culturas e aspectos da vida quotidiana que tinham sido negligenciados pela historiografia tradicional" $\left({ }^{62}\right)$.

Os factores de localização industrial e as alterações a que - a médio e a longo prazo - estão sujeitos constituem um tema da maior acuidade, não só do âmbito da história económica como da geografia, da economia e das estratégias do desenvolvimento. Entre os referidos factores, destacam-se os seguintes: matéria-prima, matéria auxiliar, energia, mão-de-obra, indústria (na medida em que indústria atrai indústria ou desenvolvimento induz desenvolvimento), capital, mercado, infraestruturas e intervenção política. Trata-se de um numeroso conjunto de temáticas, cuja abordagem muito beneficiará com o recurso aos métodos da arqueologia industrial. Assim, não só se alarga consideravelmente a categoria dos bens culturais ambientais, como se concretiza a operação conceptual da passagem de uma "arqueologia industrial" ao estudo da "cultura material da revolução industrial". Tal operação deve ser acompanhada da abertura a novos conteúdos, do aprofundamento do método e de um maior desenvolvimento no diálogo interdisciplinar $\left({ }^{63}\right)$.

As condições materiais, técnicas e ambientais da produção artística, artesanal e ambiental devem ser estruturadas a partir do concreto e dos próprios testemunhos materiais. É que, nas mencio-

${ }^{\left({ }^{6}\right)}$ George G. Iggers, New directions in European historiography, ed. revista, Londres, Methuen, 1985, p. 203-204.

( $\left.{ }^{63}\right)$ Sobre a questão dos factores de localização industrial, ver a elucidativa síntese efectuada por Mario Mantelli, "I fattori delia localizzazione industriale", L'Ambiente Storico. Archeologia Industrial in Piemonte, 1979, 1/2, p. 21-27. 
nadas condições, entrecruzam-se factores diversos, quer de índole histórico-cultural - tradição, "know- how", bloqueios —, quer de índole conjuntural - inovação, contexto favorável do ponto de vista do mercado, etc. Reportando-se a alguns dos factores acima indicados, sublinha Henri Focillon: "O artista que corta a sua madeira, bate o seu metal, amassa a sua argila, talha o seu bloco de pedra, traz até nós um passado do homem, um homem antigo, sem o qual nós não existiríamos. Não é admirável ver de pé, entre nós, na idade mecânica, este sobrevivente obstinado das eras das mãos? Os séculos passaram sobre ele sem alterar a sua vida profunda, sem o fazer renunciar às suas antigas formas de descobrir o mundo e de o inventar. A natureza é sempre para ele um receptáculo de segredos e maravilhas"

Porém, o conhecimento das condições concretas em que o homem actua, ao transformar a matéria- prima, não interessa apenas em relação à actividade artística e artesanal, mas também à compreensão da própria dinâmica industrial. Como destacam Philipp Breton e outros, "longe de o artesão ou o engenheiro dominarem o que aparece como a sua obra, eles operam no quadro dos constrangimentos e solicitações através dos quais se dedicam a realizar o que o equipamento técnico torna possível a partir de uma herança. Esta herança religa-os sem descontinuidade aos inícios da indústria hominiana, de há vários milhões de anos. Eles realizam as potencialidades [da herança e condições disponíveis], como que envolvidos nesta exteriorização e autonomização das formas induzidas pela

$\left(^{(4)}\right.$ Henri Focillon, $O$ elogio da mão. Extractos traduzidos e adaptados para a Exposição "As Mãos Vêem ", Lisboa, Fundação Calouste Gulbenkian - Museu Calouste Gulbenkian, 1980, p. inum. (Também publicado - ainda que com ligeiras alterações na tradução - em Henri Focillon, $O$ mundo das formas - $O$ elogio da Mão, col. "Origem", vol. 3, Porto, Edições Sousa \& Almeida, Lda., s.d., p. 119-147; a passagem citada encontra-se na p. 132). 
procura de um domínio eficaz sobre as coisas" $\left({ }^{65}\right)$.

A estética industrial - mais vulgarmente referenciada como "design"—reveste-se de uma importância fundamental, não só para a história da arte, do gosto e das mentalidades, como para a própria história económica. Quanto à relação entre a mencionada estética industrial e a história da arte, destaca Basilio Uribe:"[...] a estética industrial não é um fenómeno artístico propriamente dito, mas as suas repercussões sociais são extremamente importantes para a arte, pois que elas permitem elevar o nível cultural indispensável à apreciação estética" $\left({ }^{66}\right)$.

Sobre as conexões entre o "design" e a história económica, há que referir, desde logo, as próprias ligações entre arte e técnica, hoje geralmente aceites. Como adverte Herbert Read, a tradicional distinção entre "belas-artes" e "artes aplicadas" é perniciosa $\left({ }^{67}\right)$. Quando muito, entre arte e técnica existirá uma diferença de tónica, a qual é colocada, respectivamente, no estético e no mecânico. É esta a opinião de Lewis Mumford, ao destacar: "Podemos acrescentar agora, para diferenciar a arte da técnica, que a arte é a parte da técnica que sofre a maior marca da personalidade humana; a técnica é aquela manifestação da arte da qual uma grande parte da personalidade humana foi excluída para favorecer o processo mecânico" $\left({ }^{68}\right)$.

Todavia, na estética industrial, além das suas vertentes estética e técnica propriamente ditas, convergem ainda outras, de natureza

${ }^{\left({ }^{65}\right)}$ Philippe Breton et al, La techno-science. Éléments pour une archéologie du XX siècle, Seyssel, Champ Valon, 1990, p. 107.

${ }^{\left({ }^{\circ}\right)}$ Basilio Uribe, "L'apport de la création des formes industrielles à l'esthétique du $\mathrm{XX}^{\cdot}$ siècle", Herbert Read et al, Les arts et la vie. Place et rôle des arts dans la société, Paris, UNESCO, 1969, p. 86.

$\left({ }^{67}\right)$ Herbert Read, $O$ significado da arte (trad. do inglês), 2a ed., Lisboa, Ulisseia, s.d., p. 31-32.

$\left({ }^{68}\right)$ Lewis Mumford, Arte \& técnica (trad. do inglês), Lisboa, Edições 70,1980, p. 24. 
económica e social. Com efeito, na evolução dos modelos dos objectos, repercutem-se factores relativos à produção, ao custo, à distribuição e ao consumo, à publicidade e à funcionalidade. Sob esta perspectiva, destaca-se "o criador de modelos [ou "designer"], cujo domínio de actividade incide sobre os produtos fabricados em série pela indústria, tendo por função pôr em prática estruturas formais harmoniosas que permitam fornecer soluções adequadas aos problemas de produção, de economia e de utilização" $\left({ }^{69}\right)$. Como recorda o autor citado (B. Uribe), "esta função é eminentemente social e o especialista de estética industrial está tanto mais consciente disso quanto é certo que ele próprio é um utilizador, entre tantos outros, dos produtos da indústria" $\left({ }^{70}\right)$.

Para o estudo de toda esta temática-em especial no que respeita aos aspectos económicos e sociais da estética industrial-, a arqueologia industrial poderá dar importantes achegas através da detecção, preservação e análise de séries de objectos, bem como de testemunhos com eles relacionados. Entre estes, podem apontar-se moldes, desenhos, catálogos, máquinas e utensílios. Não será ousado prever, inclusive, que a investigação, baseada nas ditas fontes, venha a adquirir maior importância, à medida que o próprio "design" se for desenvolvendo, na sequência do que tem vindo a verificar-se nas últimas décadas. Sobre o assunto, escreveu S. Giedion: "O "designer" não se contenta em traçar linhas e curvas. Os "ateliers" das grandes casas de estética industrial, que empregam mais de uma centena de desenhadores, ocupam-se igualmente de estudos de mercado, da reorganização de armazéns e fábricas assim como de plantas de imóveis. Assim o "designer" deve ser simultaneamente decorador, arquitecto e organizador" $\left({ }^{71}\right)$.

(") Uribe, op. cit., p. 85.

$\left(^{70}\right)$ Uribe, ibidem.

(11) Siegfred Giedion,La mécanisation au pouvoir. Contribution à l'histoire anonyme, 
Como é do conhecimento geral, os transportes e comunicações constituem um dos temas fulcrais da história económica. Com efeito, com ele se relacionam, de forma mais ou menos directa, entre outros, assuntos como os seguintes: a relação espaço-tempo, com todas as suas implicações; o aprovisionamento e o abastecimento; os custos e os preços; a mão-de- obra e o respectivo custo; a concorrência entre agentes económicos e o desenvolvimento urbano. Trata-se, com efeito, de um tema muito vasto, ultrapassando largamente a perspectiva limitada das relações comerciais, através da qual tem sido vulgarmente equacionado. Apresenta-se como decisivo em qualquer dinâmica de mercado, ao mesmo tempo que permite delimitar, a partir de bases mais sólidas, os espaços-zonas, áreas, regiões - a eleger como objecto de estudo pela história económica ou disciplinas afins.

Além do caminho-de-ferro-que, pelo menos em certos países, como a Grã-Bretanha, tem merecido certa atenção $\left({ }^{72}\right)-$, outros assuntos devem ser investigados, segundo uma óptica pluridisciplinar. Através dos vestígios materiais - embarcações, portos fluviais e marítimos, veículos, estruturas como canais, pontes, túneis e estradas - , poder-se-á aprofundar o escasso conhecimento que possuímos em tais domínios, particularmente da época pré-industrial. Relativamente às últimas duas centúrias—desde os inícios da revolução industrial—, muito há igualmente que investigar, para além do que já se conhece a partir das fontes escritas. Atente-se, por exemplo, nas seguintes problemáticas, cujo esclarecimento poderá ser aprofundado com a ajuda da arqueologia industrial: transferência de tecnologia, condições e respectivos agentes; evolução

t. III: La mécanisation à la maison (trad. do inglês), Paris, Centre Georges Pompidou/ CCI, 1980, p. 84.

$\left(^{12}\right)$ M. J. T. Lewis, "Industrial archaeology", Carlo M. Cipola (ed.), The Fontana Economic History of Europe, vol. 3: The industrial revolution, 1700-1914, Londres, Harvester Press/Barnes \& Noble/Fontar.a Books, 1976, p. 587. 
comparativa dos veículos e vias de transporte e sua relação com o contexto socioeconómico; inventores e inovadores no ramo dos transportes e comunicações, dos quais só um pequeno número é recordado. Em virtude do acelerado desenvolvimento tecnológico, verificado nos transportes/comunicações, em especial no último meio século, torna-se urgente preservar parte do numeroso património industrial que, uma vez desactivado, corre o risco de desaparecer a curto prazo, como, aliás, tem vindo a acontecer com alguma frequência. Através de um trabalho conjunto, entre arqueólogos industriais e museólogos, há que constituir colecções de veículos $\left({ }^{73}\right)$ ou objectos vários - inerentes aos respectivos sistemas de trans-portes e comunicações - , a fim de que ainda seja possível salvaguardar uma parte significativa do "mundo que nós perdemos" — para usar a expressão de Peter Laslett $\left({ }^{74}\right)$ — e que, se não tivermos cuidado, continuaremos a perder.

As condições de trabalho e de alojamento, frequentemente abordadas sob uma perspectiva ideológica e polémica - na óptica de uma certa e gradual pauperização do operariado, admitida por uns e negada por outros - , poderão ser reequacionadas, à luz da metodologia proposta pela arqueologia industrial. Para tal, há que investigar as estruturas ainda existentes ou seus vestígios, quer sejam oficinas ou manufacturas, fábricas ou centrais - eléctricas, de produção de gás, elevatórias de água, etc-, bairros operários ou residências de empresários, gestores ou quadros. De que condições dispunham os utentes desses espaços, sob diversos pontos de vista:

$\left(^{13}\right)$ Apenas a título de exemplo, recordo a experiência interessante levada a cabo pelo "Birmingham Museum of Science and Industry" (Grã-Bretanha), ao reunir uma importante colecção de bicicletas. Como é sabido, embora tratando-se de um tipo de veículo bastante popular, tem-se dedicado pouca atenção aos numerosos modelos que assumiu e que hoje são praticamente desconhecidos.

${ }^{(7)}$ Peter Laslett, $O$ mundo que nós perdemos (trad. do inglês), Lisboa, Ed. Cosmos, 1975. 
área disponível—o que aponta para a respectiva densidade populacional-, luminosidade, condições de abastecimento de água e energia, saneamento, acessos, etc. As referidas temáticas deverão ser estudadas diacronicamente, de modo a poder atender-se não só aos factores mais evidentes - investimentos, localização, aproximação de outras estruturas - , mas também àqueles que se encontram dependentes da própria evolução tecnológica. Neste caso, interessa focar a técnica de construção e o uso de novos materiais - ferro, vidro, betão - , bem como as alterações que, em função desses novos elementos, se foram introduzindo. Apenas para exemplificar, recordo a iluminação- natural, através de clarabóias e janelas, a gás e eléctrica - e a sua extraordinária dependência das inovações tecnológicas, na indústria do vidro e na produção de gás e de electricidade.

Um outro assunto importante, no âmbito da história económica, é o da tecnologia. Embora não se deva sobrevalorizar o papel daquela no contexto do desenvolvimento, erro não menos grave seria o de a esquecer pura e simplesmente, como muitas vezes tem sido feito. Também neste domínio a interdisciplinaridade começa a dar bons resultados. Nesse sentido, a tecnologia não só deverá ser perspectivada através do recurso às ciências humanas, como ela própria deverá ser considerada uma ciência humana. A.G. Haudricourt, sob este ponto de vista, afirma designadamente: "1. - Para tornar-se uma ciência, a tecnologia deve tornar-se uma ciência humana. E, 2. - - as outras ciências humanas permanecerão incompletas enquanto lhes faltar a tecnologia" $\left({ }^{75}\right)$. A concluir o seu importante trabalho sobre A tecnologia, ciência humana, o autor citado conclui: "nós diremos que a técnica é a actividade mais racional do homem, e a mais característica. Esta actividade, mesmo 
sob a sua forma individual, não é biologicamente adquirida à nascença, mas socialmente apreendida e socialmente transmitida. As actividades técnicas dum grupo humano não foram inventadas apenas por esse grupo, mas provêm, em parte, das técnicas das gerações passadas, e das dos outros grupos vizinhos. A sua originalidade consiste sobretudo na combinação nova de elementos preexistentes pedidos às técnicas já conhecidas e numa melhor adaptação às circunstâncias locais, bem mais que numa "criação inspirada" a partir do nada" $\left({ }^{76}\right)$.

De acordo com esta inovadora perspectiva da tecnologia, esta passa a ter um significado muito mais rico, recheado de elementos humanos e sociais, superando-se assim a visão tradicional, demasiado tecnicista. Consequentemente, novos vectores devem ser investigados, de preferência no quadro alargado do longo prazo. Refiro-me, concretamente, à invenção e à inovação, à aprendizagem, à tradição e ao património. No que à transmissão de conhecimentos diz respeito, já se afirmou: "Resultados do passado, das informações acumuladas no dia-a-dia nos lugares de produção, assimilando e transformando os conhecimentos mais formalizados transmitidos pelo sistema de formação, os saber-fazer operários são a condição sine qua non de toda a produção industrial, e a variável-chave da transformação técnica real" $\left({ }^{77}\right)$. Todavia, para dar resposta a estas novas questões, sobre uma realidade já tão antiga, necessário se torna recorrer a novos testemunhos, designadamente materiais. Aqui se insere, uma vez mais, o papel da arqueologia industrial, com a sua metodologia adequada ao tratamento daquele tipo de testemunhos.

Por último—não por ter esgotado o assunto, mas por limitações

$\left(^{76}\right)$ G. Haudricourt, idem, p. 332.

(") A. Baret e C. Mercier, apud Michel Noele Aimé Bocquet, Les hommes et le bois. Histoire et technologie du bois de la préhistoire à nos jours, Paris, Hachette, 1987, p. 229. 
inerentes a uma lição - convirá recordar a chamada cultura material, nas suas conexões com a história económica e com a arqueologia industrial. A despeito de se tratar de uma noção ainda relativamente recente-pois só a partir dos anos 1920 começou a adquirir contornos mais nítidos - , as características que lhe têm sido apontadas permitem colocar, sem reservas, a própria cultura material no âmbito da história económica. É o que se deduz, por exemplo, das seguintes particularidades: "A cultura material pode ser definida antes de mais como a cultura do grosso da população" $\left({ }^{78}\right)$. "Nessa qualidade, [a cultura material] possui dois dos seus aspectos principais: a colectividade (oposta à individualidade) e a repetição (por oposição ao acontecimento) dos fenómenos que a compõem, o que, em qualquer ciência, define uma importante situação epistemológica e, por conseguinte, opções ideológicas e metodológicas". "Além disso-prosseguem R.B. e J.-M. Pesez—, esta aproximação cultural é determinada pela angularidade da materialidade, que foi a escolha para essa abordagem, tal como indica o objectivo "material". Esta escolha da materialidade revela dois aspectos preciosos: o apego aos fenómenos infra-estruturais como causalidade heurística e a atenção aos objectos concretos que explicam esses fenómenos" $\left({ }^{79}\right)$.

Como se pode deduzir do que fica exposto, a cultura material tem laços muito estreitos com a história económica - já que, uma e outra privilegiam o colectivo, as massas e os fenómenos de recorrência-e com a própria arqueologia industrial, pela via do concreto, dos objectos materiais. Como lembram os autores anteriormente citados, "na história, por exemplo, sucede com frequência

$\left({ }^{78}\right)$ Richard Bucaille e Jean-Marie Pesez, "Cultura material", Enciclopédia Einaudi, vol. 16: Homo-Domesticacão. Cultura material, Lisboa, Imprensa Nacional-Casa da Moeda, 1989, p. 21.

$\left({ }^{19}\right)$ R. B. e J.-M. Pesez, ídem, p. 25. 
que os contactos económicos entre civilizações muito distantes entre si sejam apenas confirmados pelos objectos materiais, culturalmente típicos, que elas trocam entre si" $\left({ }^{80}\right)$.

Em conclusão: Por um lado, fazem parte da cultura material temas (como os meios de produção extraídos da natureza, as forças de produção e os produtos materiais $\left.\left({ }^{81}\right)\right)$ que, por sua vez, constituem como que o "núcleo duro" da própria história económica. Por outro lado, dada a natureza (fundamentalmente material) das fontes para o estudo dos mencionados temas, a arqueologia industrial, com a sua metodologia específica, constituirá um importante meio de abordagem, podendo dar, como tal, uma excelente colaboração à pesquisa histórica.

\subsection{Metodologia}

Sob o ponto de vista metodológico, também a arqueologia industrial pode prestar uma significativa ajuda à história económica. Com vista a recorrer, sempre que tal se justifique, às fontes materiais - como, aliás, tenho vindo a sublinhar —, toma-se absolutamente necessário efectuar trabalho de campo. Também, neste caso, a experiência do método utilizado em arqueologia industrial se revelará extraordinariamente vantajoso ao investigador da história económica. Apesar de não se tratar, propriamente, de uma novidade, trata-se de uma prática ainda pouco vulgar, entre os historiadores. Sobre o assunto, já foi sublinhado - embora talvez com algum optimismo—o seguinte: "A época em que os historiadores pensavam em não trabalhar senão com testemunhos escritos acabou há muito

$\left({ }^{80}\right)$ R. B. e J.-M. Pesez, ibidem. Ver também, do mesmo trabalho, p. 26-33 ("Cultura material e história") e 33-35 ("Cultura material e história económica e social").

$\left({ }^{81}\right)$ Cfr- RB. e J.-M. Pesez, idem, p. 35. 
tempo. Já Lucien Febvre sugeria que se tomassem em consideração as ervas, a forma dos campos, os eclipses da lua" $\left({ }^{82}\right)$.

Concretizando um pouco mais o trabalho de campo, acima referido, ele poderá ser de grande utilidade, por exemplo, no que respeita à história das empresas. Ainda que o seu alcance ultrapasse, largamente, o âmbito da história económica, esta muito aproveitará com o desenvolvimento da dita história das empresas que, a exemplo do que tem sucedido noutros países-Estados Unidos da América, Grã-Bretanha e França, entre outros $\left({ }^{83}\right)$ - urge incentivar em Portugal. Na referida história, além da metodologia da história tradicional- utilizada na exploração das fontes arquivísticas pertencentes às empresas - há toda a vantagem em focar o respectivo património industrial por meio da metodologia da arqueologia industrial. É que, apesar de algumas empresas possuírem arquivos dotados de acervos excepcionais, outras - por motivos diversos que não interessará aqui especificar - apenas conservam em arquivo a documentação mais recente e, mesmo essa, nem sempre em condições de ser consultada. Nesses casos, o investigador em história económica, auxiliado metodologicamente pelo arqueólogo industrial, poderá colmatar as lacunas das fontes escritas-ou da sua ausência-recorrendo, por exemplo, à análise dos seguintes elementos: instalações ou seus vestígios; tecnologia, em actividade ou já desactivada; estruturas fixas, como fornos-na cerâmica e no vidro-, caldeiras, chaminés, etc ; matérias-primas, moldes e artigos;

$\left({ }^{82}\right)$ Carlo Ginzburg, apud Massimo Tozzi Fontana, "Le regard de l'archeologue industriel sur l'art de l'Emile-Romagne", TICCIH. Industrial Heritage- Austria 1987, 2: Conference papers and results, Austria, Ute Georgeacopol-Winischhofer/Peter Swittalek/Manfred Wehdorn, 1990, p. 239-240.

$\left({ }^{83}\right)$ Para se obter uma visão global sobre o assunto, veja-se Maurice Hamon e Félix Torres (dir.), Mémoire d'avenir. L'histoire dans l'entreprise. Actes du l." Colloque d'Histoire appliquée aux entreprises organisépar Saint-Gobain et Public Histoire. Blois 21-22 mais 1985, Paris, Economica, 1987. 
meios de transporte; sistema de abastecimento de energia, como barragens, levadas, aquedutos e rodas hidráulicas. Acrescente-se, ainda, que mesmo no que se refere à exploração de outros tipos de fontes - postais ilustrados, gravuras, papel timbrado, anúncios e diplomas obtidos em certames —, a experiência metodológica da arqueologia industrial poderá enriquecer a própria metodologia da história económica.

\section{Conclusão}

Pelo que se acaba de expor, a história económica, já exercitada no "diálogo" com outras disciplinas - entre as quais, sociologia, estatística, economia e geografia -, muito beneficiará, do ponto de vista científico, metodológico e didáctico, se vier a estabelecer laços de mais estreita colaboração com a arqueologia industrial. Fazendo-o, não só se libertará, em certa medida, da "escravatura" das fontes escritas, como poderá focar, com maior segurança, períodos e temas - incluindo a própria biografia — para os quais não é possível dispor de séries — completas e homogéneas—, nas quais se têm baseado fundamentalmente os estudos de história económica. Por outro lado, do ponto de vista pedagógico-didáctico e ultrapassando o âmbito da história económica, a arqueologia industrial tem potencialidades que lhe permitem tornar o processo ensino-aprendizagem mais concreto, activo e motivador, visto apelar para realidades facilmente observáveis pelos respectivos agentes. O estudo do património industrial poderá ainda contribuir para reforçar a cultura técnica e científica, sem a qual não haverá uma boa e sólida cultura geral. A propósito, eu finalizaria com as seguintes palavras de Einstein, proferidas por volta de 1920, mas ainda pertinentes, em nossos dias: "A escola não pode ser [só, acrescentaria eu] uma fonte de jurisprudentes, literatos e advogados, nem meramente de má- 
quinas mentais". E prossegue, o autor da teoria da relatividade: "Prometeu, segundo o mito, não começou a ensinar os homens pela astronomia, mas principiou pelo fogo e suas propriedades e usos práticos" $\left({ }^{84}\right)$.

$\left({ }^{84}\right)$ "Palavras de uma entrevista dada por Einstein, por volta de 1920, e publicada em O Jornal do Rio de Janeiro", apud Ruy Gama, A tecnologia e o trabalho na história, São Paulo, Nobel/EDUSP, 1987, p. 213. 